\title{
Erratum to: Pelvic CT angiography in blunt trauma: imaging findings and protocol considerations
}

Jennifer Uyeda, Stephan W. Anderson, Jennifer Kertesz, James T. Rhea, Jorge A. Soto Department of Radiology, Boston University Medical Center, 715 Albany Street, Boston, MA FGH-3007, USA

\section{Erratum to: Abdom Imaging DOI 10.1007/s00261-009-9525-8}

The article title by Uyeda J, Anderson SE, Kertesz J, Rhea JT, Soto JA. Pelvic CT angiography: application to blunt trauma using 64 MDCT published online on May 21, 2009 has been modified to "Pelvic CT angiography in blunt trauma: imaging findings and protocol considerations".

The online version of the original article can be found under doi:10.1007/s00261-009-9525-8.

Correspondence to: Jennifer Uyeda; email: Jennifer.Uyeda@bmc.org 